\title{
Re-intervention for recurrent biliary obstruction after endoscopic ultrasound hepaticogastrostomy with partially covered self-expandable metal stent
}
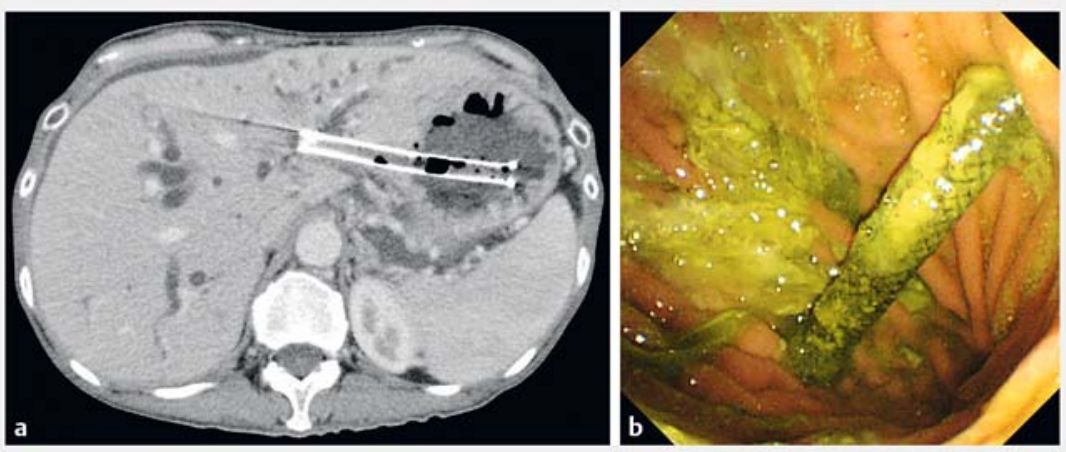

- Fig. 1 Recurrent biliary obstruction after endoscopic ultrasound-guided hepaticogastrostomy shown on: a computed tomography image; $\mathbf{b}$ endoscopic view.
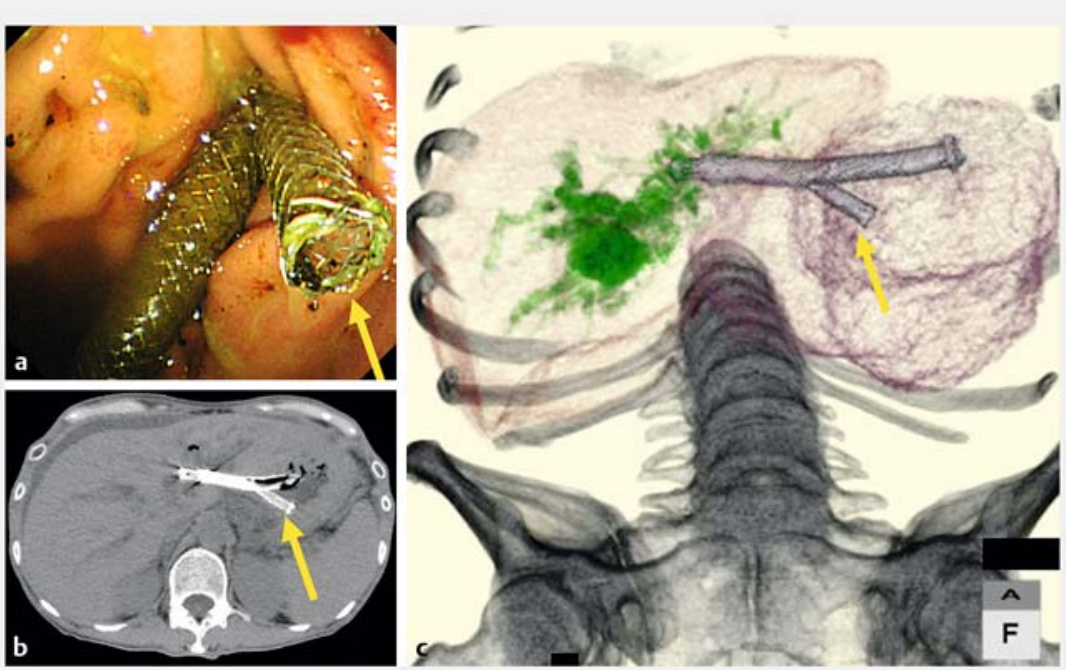

- Fig. 3 A fully covered self-expandable metal stent (arrow) is positioned through the previously placed stent, as shown on: a endoscopic view; b computed tomography (CT) image; c reconstructed $\mathrm{CT}$ image.

The use of the endoscopic ultrasoundguided hepaticogastrostomy (EUS-HGS) method for malignant biliary stricture has increased. A partially covered self-expandable metal stent (PCSEMS) is often selected for the procedure, and re-intervention is challenging because of the long length of stent protrusion inside the stomach. Several re-intervention methods, including trimming and stent penetration using electrical devices, have been reported [1-4]; however, the complexity and time-consuming nature of these procedures pose limitations. Here, we report the simplest of novel reintervention methods for PCSEMS dysfunction after an EUS-HGS.

A 65-year-old woman with unresectable pancreatic cancer and duodenal obstruction underwent EUS-HGS using a PCSEMS

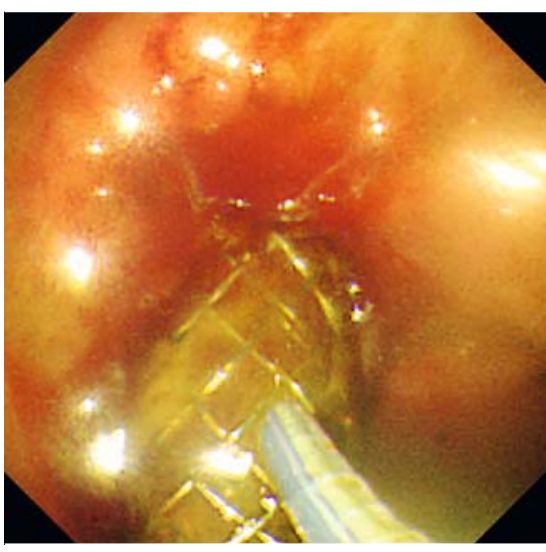

- Fig. 2 Endoscopic view showing a 0.025 -inch guidewire and a catheter penetrating through the mesh of the previously placed hepaticogastrostomy stent near the stomach wall.

(Niti-S biliary S-type; $8-\mathrm{mm} \times 10-\mathrm{cm}$ covered stent with a $1-\mathrm{cm}$ uncovered portion; Taewoong Medical, Seoul, South Korea). After 8 months had passed, recurrent biliary obstruction occurred due to bile duct hyperplasia at the stent edge ( Fig.1). Stent removal with a grasping forceps was not possible because it was firmly anchored by the overgrown tissue. Inserting a guidewire and a catheter parallel to the stent to access the bile duct was also not feasible.

We therefore penetrated the stent mesh close to the stomach wall with a guidewire (Visiglide2; Olympus, Tokyo, Japan) and a catheter (Tandem XL ERCP Cannula; Boston Scientific Corporation, Marlborough, Massachusetts, USA). These devices were advanced into the stent ( $\triangleright$ Fig.2), and bypassed the stricture allowing access to the bile duct. The biliary stricture and the stent mesh, at the entry point of the wire and catheter, were dilated with a balloon catheter (REN; 8-mm wide; Kaneka Medix Corporation, Tokyo). A fully covered SEMS (Niti-S biliary S-type; $6-\mathrm{mm} \times 8-\mathrm{cm}$ long covered stent; Taewoong Medical) was threaded through the dilated tract and successfully de- 


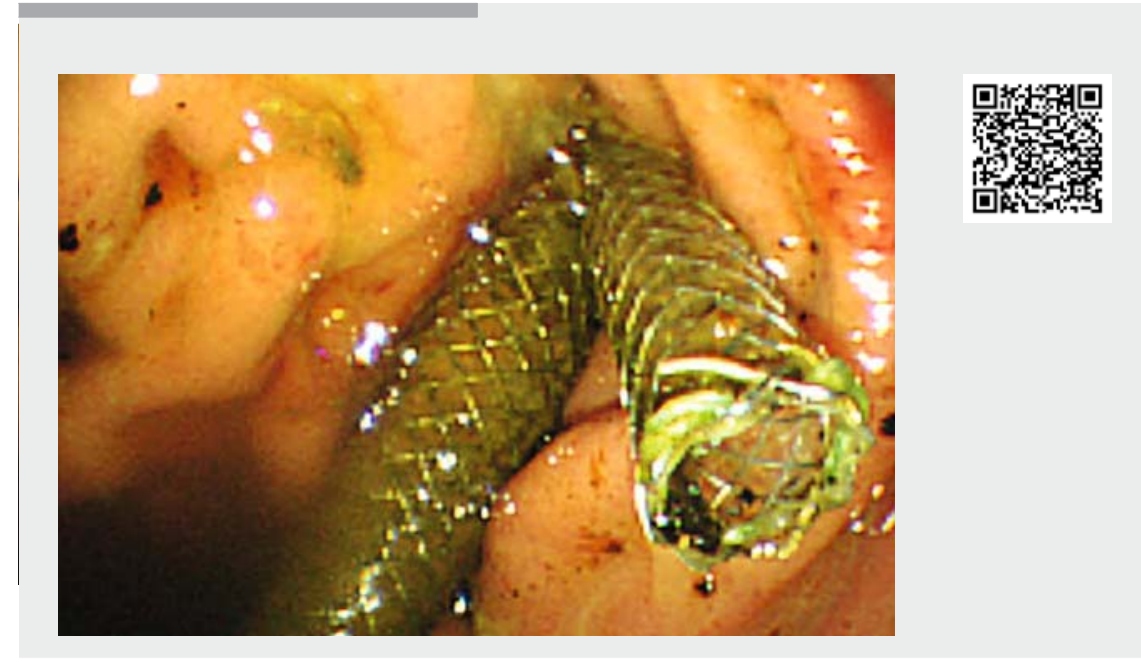

$\checkmark$ Video 1 The video shows a novel re-intervention method for recurrent biliary obstruction after endoscopic ultrasound-guided hepaticogastrostomy with a partially covered self-expandable metal stent.

ployed ( $\vee$ Fig. $3, \triangleright$ Video 1$)$. This procedure was completed without any adverse events.

This novel re-intervention method involving penetration of the stent mesh near the stomach wall is simple, safe, and efficient.

Endoscopy_UCTN_Code_CPL_1AL_2AD

\section{Acknowledgment}

This work was supported in part by The National Cancer Center Research and Development Fund 31-A-13.

Competing interests

None

\section{References}

[1] Yane K, Katanuma A, Maguchi $\mathrm{H}$ et al. Successful re-intervention with metal stent trimming using argon plasma coagulation after endoscopic ultrasound-guided hepaticogastrostomy. Endoscopy 2014; 46: E391-E392

[2] Hamada T, Nakai Y, Isayama $\mathrm{H}$ et al. Trimming a covered metal stent during hepaticogastrostomy by using argon plasma coagulation. Gastrointest Endosc 2013; 78 : 817

[3] Minaga K, Takenaka M, Okamoto A et al. Reintervention for stent occlusion after endoscopic ultrasound-guided hepaticogastrostomy with novel use of a precut needleknife. Endoscopy 2018; 50: E153-E154

[4] Ogura T, Masuda D, Takeuchi T et al. Simplified reintervention method of EUS-guided hepaticogastrostomy stent obstruction. Gastrointest Endosc 2016; 83: 831

\section{Bibliography}

DOI https://doi.org/10.1055/a-0915-1718

Published online: 23.5.2019

Endoscopy 2019; 51: E297-E298

(c) Georg Thieme Verlag KG

Stuttgart · New York

ISSN 0013-726X

Sakamoto ${ }^{1}$, Takuji Okusaka ${ }^{1}$, Yutaka Saito ${ }^{2}$

1 Department of Hepatobiliary and Pancreatic Oncology, National Cancer Center Hospital, Tokyo, Japan

2 Endoscopy Division, National Cancer Center Hospital, Tokyo, Japan

\section{Corresponding author}

\section{Susumu Hijioka, MD}

Department of Hepatobiliary and Pancreatic Oncology, National Cancer Center Hospital, 5-1-1 Tsukiji, Chuo-ku, Tokyo, Japan Fax: +81-3-35423815

shijioka@ncc.go.jp 